\title{
Preliminary Exploration on the Application of Saussure Sign Concept in Bio-Inspired Design: A Case of Tiantoushui Doll-Design
}

\author{
Yu-Chun Yao', Shiu-Hua Wu ${ }^{2 *}$, Ai-Li Wang ${ }^{3}$ \\ ${ }^{1}$ Graduate Program of Sustainable Tourism and Recreation Management, National Taichung University of Education, \\ Taichung \\ ${ }^{2}$ Department of Digital Media Design, Hsiuping University of Science and Technology, Taichung \\ ${ }^{3}$ School of Art and Design, Dalian Polytechnic University, Dalian \\ Email: *wuhh@hust.edu.tw
}

How to cite this paper: Yao, Y.C., Wu, S.H. and Wang, A.L. (2021) Preliminary Exploration on the Application of Saussure Sign Concept in Bio-Inspired Design: A Case of Tiantoushui Doll-Design. World Journal of Engineering and Technology, 9, 548-554. https://doi.org/10.4236/wjet.2021.93037

Received: June 25, 2021

Accepted: August 2, 2021

Published: August 5, 2021

Copyright (c) 2021 by author(s) and Scientific Research Publishing Inc. This work is licensed under the Creative Commons Attribution International License (CC BY 4.0).

http://creativecommons.org/licenses/by/4.0/

\begin{abstract}
Simply, shape bionics is to extract an image feature of natural objects, and most of the techniques for transforming and presenting are focused on metaphorical effects. In particular, the extraction process of metaphor design seems to be related to the concept of Saussure signs. Therefore, this research took the doll design of the Tiantoushui community in Changhua County, Taiwan as an example and attempted to use the Saussure concept to extract and evaluate the signs of bio-inspired design. The results showed that a total of three doll works symbolized respectively rice, guava, and pomelo implied the signification of local region by integrating the Saussure code image with the sign-image of the regional nature and transforming its content into "commodity design" and further transferring into "the product value of cultural and creative". In addition, the specific extraction process included 1) Extraction of image-adjectives in creative products; 2) Meaning space of image-adjectives in creative products; 3 ) Extraction and determination of design elements of creative products, and 4) Combined the sensibility of creative products and design elements to derive design rules. After preliminary exploration of the extraction steps above, a concrete and efficient bio-inspired design process was proposed in this work. Besides, it was inferred that if further combined with the post-modern design style, it may not only simplify the design elements of creative products but also enhance the design connotations in the future.
\end{abstract}

\section{Keywords}

Bio-Inspired Design, Saussure Sign Concept, Doll-Design, Code-Image 


\section{Introduction}

Since ancient times, human have known how to imitate nature and integrated it into life invisibly to enhance living quality of people, such as tree house, boat, plane, and so on [1]. Recently, advanced with the modern technique and economic, bionic technology pays much more and more attention. Bionics, also termed as bio-inspiration, biomimicry, biomimetics, etc., was widely applied in various multidisciplines [2] [3] [4]. However, in terms of the bio-inspired design, it simply belongs to a kind of design that imitates the outer appearance and/or function of natural creatures. In other words, after observing the creatures in nature, designers extract the specific characteristics and/or functions of the creatures. Subsequently, these characteristics are applied in the works by designers, so that the design products maybe have analogical biological characteristics, such as biological shape and color. But several scholars also suggested that the bio-inspired design is a distinct design, not an easy modification and/or selection mode [3] [5].

So-called Saussure sign concepts, that is, a sign is an entity with meaning and also consists of two components including signifier and signified. A signifier is a physical form of signs such as a sound, printed word, or image. The signified means the sense of symbol and is also a part of meaning represented the sign [6] [7]. In other words, it means understanding or ideas generated by these symbols in different communicators and receivers. Therefore, the creative designer effectively attempts to catch the sign and connotation of product image by considering the indivisible signifier-signified relationship of the aesthetic design of the subject composition [8]. The metaphor expression skill in Saussure semiotic concepts is increasingly applied in the discipline of design in recent years, particularly in the creative products (CPs) [8] [9] [10]. Also, the design purpose of CPs is to enhance the purchasing behavior of consumers. Therefore, in addition to purchasing the real values of commodities, they also consume the meaning, beauty, and sentiment of products that symbolize and represent.

Tiantoushui communities including Tianchung, Shetou, and Ershui towns located in the central territory in Taiwan, produced mainly on agricultural products before. But advanced with social economic and a lot of creative products (CPs), the CPs in the market have gradually shifted from function-orientation to psychological needs, which will further induce the satisfaction of psychological level of product-image. Therefore, this work focused on doll-design which represents the meanings of agricultural products of Tiantoushui, by combining with the extracted procedure of Saussure code concept and the sign-image of bio-inspired design.

\section{Methods}

\subsection{Extraction Symbol Image of Creative Products}

In order to draw out the metaphor sign that represented the code-image of agricultural commodities of Tiantoushui territory, four design-steps modified from 
previously reports which described the conception of Saussure sign [6] [11] were further concluded in this work, as shown in Figure 1.

\subsection{Converting a Flat Graphic to a Three-Dimension Doll}

Through these steps extracted metaphor code, the authors would conclude some design elements of organic products and apply to the doll design of three-dimension (3D) by using the texture of wool felt. Briefly, the artificially assembled procedures of $3 \mathrm{D}$ creative dolls included 1) roll-up first the wool tightly, 2) poking the end of the doll to fix the wool, then repeating the first step, 3) molding the shape, and 4) sticking the different colors of wool. Finally, the different types of $3 \mathrm{D}$ dolls with wool felt were completed from a flat image code. Figure 2 showed that the 3D doll with wool felt was being artificially assembled using a like stick-needle tool by a creative designer according to the extracted sign steps described above.

\section{Results and Discussion}

\subsection{Extraction Symbol Image of Creative Products}

Simply, semiotics is a discipline that studies signs. As we known, the various cultures generally derive different symbolic meanings. In the terms of generalized semiotics, it can almost cover all regular expression modes and characteristics

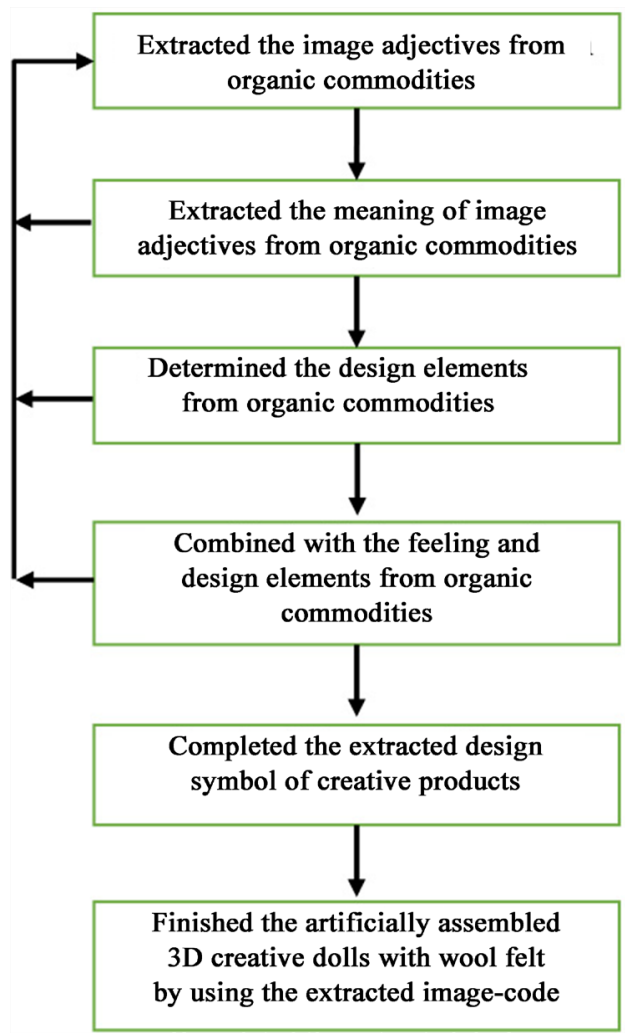

Figure 1. The flowchart of extracted steps from organic commodities by combining with Saussure code concept and bio-inspired design, as well as the artificially assembled 3D creative dolls with wool felt. 
other than language [12]. However, Derrida (1982) also pointed out that the cognition of sign results from the socialization, and there was no one-to-one direct relation between the signifier and the signified [13]. Therefore, the focus in this work was to first extract the code-image of agricultural commodities of Tiantoushui community based on the Saussure sign concept.

After extracted the meaning symbols through the extraction procedures of this study, the authors finally completed three piece of creative works. As shown in Figure 3, the arc line code of pink-white implied that only good soil and water quality could cultivate good rice quality. The line-code of turquoise like represented the feelings of crispy and sweet guava. Because there is a fertile black soil resulted in alluvial plain beside the Zhuoshui-River, it can nourish the precious guava. From the early production time of Tu-Guava and Thai-Guava to the Pearllike Guava, it has always been the production king of Guava in Taiwan. Also, the golden-yellow lines represented the imperial-like pomelo, which was not only juicy and delicious, but also spread somewhat aroma. After extracted the codeimage of bio-inspired, the designed procedures of transformation were further showed in Figure 4, respectively.

For example, the green leaves drew on the upper half of the graphics even suggested that the quality of agricultural products produced by natural cultivation
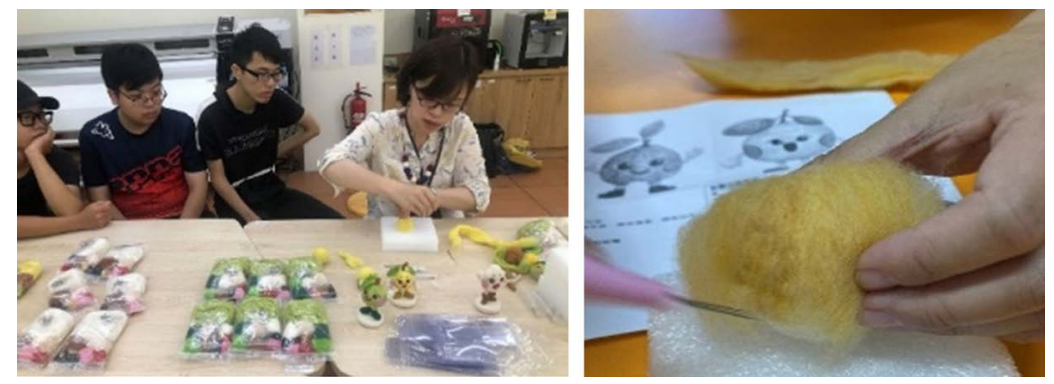

Figure 2. Illustrated 3D doll of wool felt was being assembled by hand with a stick tool. Left panel: the designer was displaying the merging steps. Right panel: the operation illustration was amplified.

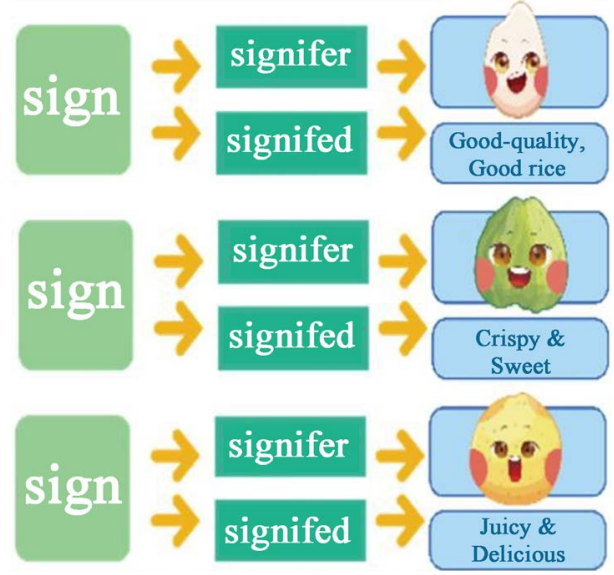

Figure 3. The diagram of code-image extracted from agricultural commodities based on Saussure sign concept. 


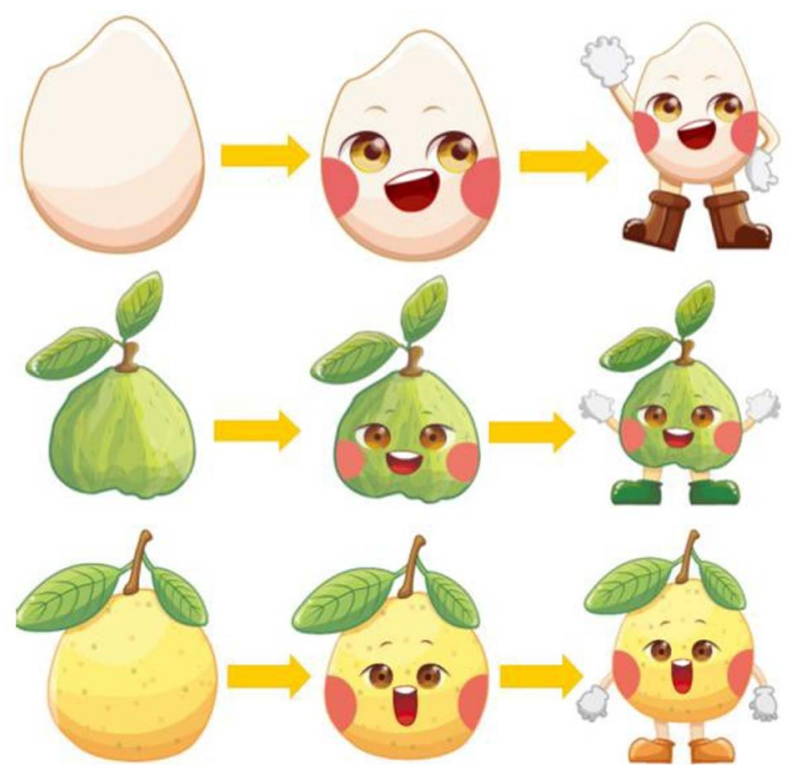

Figure 4. The diagrams of the designed procedures of transformation in bio-inspired.

method was the best than that of non-natural method (Figure 4). On the other hand, many colors are covered in nature, and will also alter with the change of the four seasons. The previous papers show that the colors will make lots of creatures including human physiology and psychology have wonderful feelings of resonance at any time [14] [15]. For a designer, the color can be considered as a kind of packaging design which is attached to the exterior of any creative design products and/or objects. Therefore, coordinated color-design and color planning can not only beautify the design of creative products but also effectively and directly enhance the competitiveness of commercial products [16]. Besides, the evidence also showed that this bio-inspired design should be somewhat different from the simple modification and selection design method previously described elsewhere [3] [5]. In other words, if designers just do a simple modification and/ or selection, the creative work will finally result in fail due to the losing spirit characteristics inspired by natural objects. Therefore, the elements and meanings of code-image bio-inspired should be completely displayed in the creative works.

\subsection{Converting a Flat Graphic to a Three-Dimension Doll}

Subsequently, after extraction the elements of code-image based on the designsteps, they were further applied to doll-design of $3 \mathrm{D}$ using the texture of wool felt (Figure 5). The texture of wool felt belongs to a non-woven fiber fabric. It has some well physical properties, such as strong flexibility, well water-resistance, good warmth retention, non-flammability, noise-reduction, and so on [17]. Therefore, designers can create beautiful products according to the characteristics of wool felt, thereby producing a series of influential works to meet the different aesthetic viewpoints and fashion-demands of consumers. In this work, the 3D-dolls imitated the agricultural commodities were further completed, they not only 


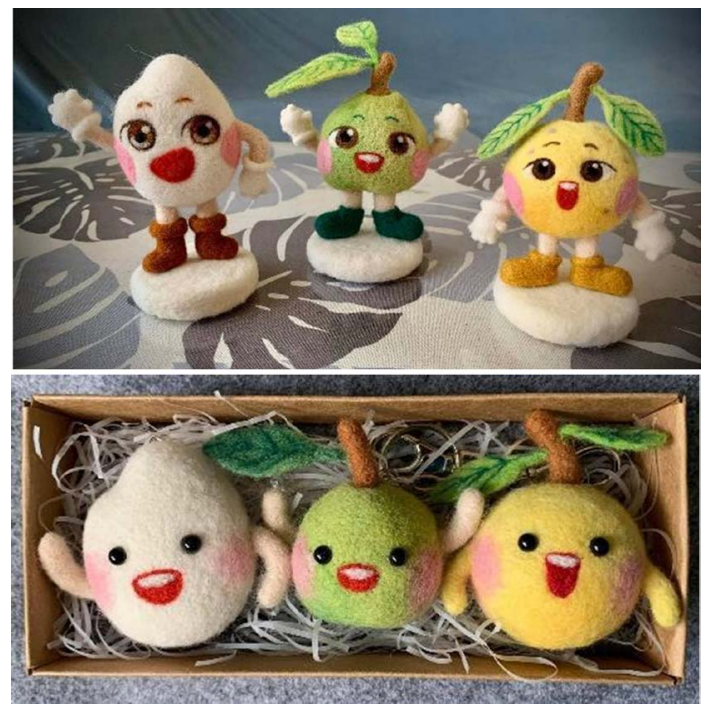

Figure 5. The diagram of 3D creative dolls based on the extraction signs was artificially made from the texture of wool felt

showed the compound metaphor of commodities but also might have the potential for promoting agricultural products in view of their cute and vivid shapes.

\section{Conclusion}

The symbol of code-image was extracted from the agricultural commodities of Tiantoushui territory by using the extraction procedures based on Saussure sign concept. A total of three pieces of creative dolls which imitated the natural agricultural commodities was preliminary completed in this study. The evidence suggested that the extraction procedures of code-image based on Saussure sign concept from biological products might have a potential for application on bio-inspired design in the future.

\section{Acknowledgements}

The authors would like to thank the Ministry of Education for financial support for this study under the USR sub-program No. F-3-3-11.

\section{Conflicts of Interest}

The authors declare no conflicts of interest regarding the publication of this paper.

\section{References}

[1] Wang, S.Y. (2015) Research on Bionic Method in Product Design. Art Science and Technology, No. 10, 54 .

[2] Rossin, K.J. (2010) Biomimicry: Nature's Design Process versus the Designer's Process. WIT Transactions on Ecology and the Environment, 138, 559-570. https://doi.org/10.2495/DN100501

[3] Arciszewski, T. and Cornell, J. (2006) Bio-Inspiration: Learning Creative Design Prin- 
cipia. Workshop of the European Group for Intelligent Computing in Engineering, Ascona, 25-30 June 2006, 32-53. https://doi.org/10.1007/11888598 5

[4] Mueller, T. (2008) Biomimetics: Design by Nature. National Geographic, 213, 68-91.

[5] Altshuller, G.S. (1984) Creativity as an Exact Science: The Theory of the Solution of Inventive Problems. CRC Press, London. https://doi.org/10.1201/9781466593442

[6] Chandler, D. (2007) Semiotics: The Basics. Routledge, London. https://doi.org/10.4324/9780203014936

[7] Gordon, W.T. (2002) Saussure for Beginners. Orient Blackswan, Hyderabad.

[8] Eves, B. and Hewitt, J. (2008) Semiotics, Design Character Language. Proceedings of the 10 th International Conference on Engineering and Product Design Education (E\&PDE 2008), Barcelona, 4-5 September 2008, 573-578.

[9] Hjelm, S.I. (2002) Semiotics in Product Design. Stockholm University, Stockhom, Report No. CID-175.

[10] Zhu, S.S. and Luo, S.J. (2013) Re-Creation of Heritage Elements Based on Design Semiotics in Product Design. Journal of Zhejiang University (Engineering Science), 47, 2065-2070.

[11] Nagamachi, M. (1989) Kansei Engineering. Kaibundo Publishing Co. Ltd., Tokyo.

[12] Yang, Y.F. (2006) Cultural Basis of Design: Design, Symbols, Communication. Revised Edition 2nd Print, Ya-Tai Book Publishing House, Taipei.

[13] Derrida, J. (1982) Margins of Philosophy. University of Chicago Press, Chicago.

[14] Rider, R.M. (2010) Color Psychology and Graphic Design Applications. Senior Honors Theses, Liberty University, Lynchburg.

[15] Zhou, J. (2009) Color Design and Color Psychology. Jiangsu Textile, 3, 35-40.

[16] Yao, Y.C. and Wu, S.H. (2021) Preliminary Application of Color Design on Creative Products by Using Fuzzy Clustering Analysis-A Case of Starbucks Mug-Icon Design. Proceedings of the 2nd International Conference on Interdisciplinary Arts \& Humanities, Yogyakarta, 6 November 2020, Article ID: 3800567. https://doi.org/10.2139/ssrn.3800567

[17] Yao, X.J. (2018) Past and Present of Wool Felt Art. Fine Arts Literature, No. 2, 165 167. 